\title{
THE EFFECT OF SOME MATERIALS ON FUNNEL VISCOSITY READING IN WATER BASE MUD
}

\author{
Amel Habeeb Assi \\ Petroleum Engineering Department, College of Engineering, University of Baghdad, Baghdad, Iraq \\ E-mail: zahraa_z91@yahoo.com \\ Received: 15 February 2020; accepted: 4 May 2020
}

\begin{abstract}
Since Marsh funnel is the most famous and quick tool that used in field operations. When a crew get sample from the well and test it to show the effect of some materials on mud viscosity, it should take into consideration that there are many materials affect on the funnel viscosity like weighting materials, thinners, and polymers. Weightings material additives are essential to give adequate hydrostatic pressure to confirm borehole stability. Barium sulphate is the predominant weighting material. Many mud samples were prepared which involved freshwater, caustic soda, Bentonite, and weighting material. The weighting materials are added to mud distinctly alone to form the requisite mud density varieties between 8.7 ppg to 10 ppg. Likewise, a slight variance was detected in plastic and apparent viscosities. The experiments are done for another two substances like carboxy methyle cellulose and Lignite to show their effect on the funnel viscosity. Adding carboxy methyle cellulose led to increase the funnel viscosity, but adding Lignite led to reduce funnel viscosity. The results show that not only the viscosity affect on the funnel viscosity reading but also the density of drilling fluid have an effect on the funnel viscosity reading. The results show that when the solild percentage low about 1\% or 2\%, all the tested materials gave the same value of the funnel viscosity about (40-42) sec, that mean at low soild percentage we cannot know which material behind that change, so we should take that point into our consideration. Thus, it is concluded that mud density is another factor that affects funnel viscosity, and this point should be taken in consideration especially in-field testing and operations to avoid wrong interpretation for the tested field samples.
\end{abstract}

Keywords: Marsh funnel;Weightings material; Density; Funnel viscosity 


\section{INTRODUCTION}

A moral oil wells drilling subject to mainly on a complete drilling fluid program. Through drilling, drilling fluid is responsible for appropriate hydrostatic pressure, eliminates cuttings and calm bits. The funnel viscosity from time to time is measured by using marsh funnel. Funnel viscosity is used by means of a comparative pointer for mud condition, however it does not offer adequate evidence for concluding mud rheological properties. It only used for the field operations for noticing any relative variations. For defining fluid viscosity,we use one of the bellows expressions: Funnel viscosity sec/qt, apparent viscosity $\mathrm{cP}$, effective viscosity $\mathrm{cp}$, and plastic viscosity $\mathrm{cP}$. Plastic viscosity is termed by means of the fragment of resistance to movement produced via mechanical friction. An effective viscosity mean the fluid's viscosity underneath particular circumstances. Those situations comprise pressure; shear rate and temperature. Apparent viscosity is informed like one-half of the Van-VG meter reading on 600 RPM . Apparent viscosity is a unique mud rheological properties, apparent viscosity is measured by Van-VG meter (Bourgoyne et al.,1991).

Inequality between the hydrostatic pressure and the formation pressure may source influx of formation fluid which leads to kick and finally a blowout. Barites are environmentally welcoming if the mud is to be disposed of and that help to make good mud and avoiding us many drilling problems (Power and Zamora, 2003). The drilling fluid is formulated to have suitable hydrostatic pressure, generally in the range of 250 to 450 psi greater than the formation pressure (Ahmadi, 2007). Weighting materials raise mud density in addition to penetration rate through drilling (Bourgoyne et al., 1986). Viscosity of any fluid is the illustration a fluid's internal resistance to flow and is defined using the relationship of shear stress to shear rate. Viscosity is stated in poise or centipoise.The preferred viscosity of mud is subjective by numerous issues, including mud weight, hole diameter, pumping rate and drilling rate.

Routine field measurements mud viscosity is prepared by Marsh Funnel that measures a scheduled rate of flow in seconds. The values gained are termed "apparent viscosity" The chief viscosity structure agents in the mud are clays or essentially Bentonite, organic polymers, and oil wetting clays in oil drilling mud (Power and Zamora, 2003). These properties are usually used for predecting well pore stability and selecting drilling fluid density (Abdul Majeed and A.Alhaleem, 2020). The liquid phase of mud usually holds some additives to governor the numerous necessary properties of drilling mud, with one or more rheology additives for hanging the weighting 
materials. Rheology is created somewhat via the suspended particls and partially through extracts fluid rheology (Assi, 2017). On the other hand, a certain amount of viscosity is necessary to increase the solids carrying capacity of drilling fluid. Doubt viscosity is moreover slight; drilling fluid maybe not capable of hanging solids on the wanted pump rate. This necessitates that the pumps to be run quicker to last for circulating the solids out the well. If viscosity is excessively high, too much pressure of pum may be essential for circulating drilling fluid at the wanted rate. Higher than required pressure of the pump causes stress on pumps and increases the pressure value at the borehole which may cause borehole stability difficulties (Matthew, 2011) .

This study is carried out on unique of such weighting materials barite. Drilling fluid design involves water, Bentonite, and weighting materials. However, Mud density may be another factor that affects the funnel viscosity, and this point should be taken in consideration especially in-field testing and operation to avoid incorrect analysis. The aim of this study is to illustrate the effect of weighting materials, thinners, and carboxy methyle cellulose (CMC) on the funnel viscosity in water base mud. Also, stydying the effect of increasing of mud density on funnel viscosity.

\section{TOOLS}

\section{Marsh Funnel}

Marsh Funnel was designed by (Marsh, 1931). This tool is used for measuring period in seconds necessary for filling a fixed volume of fluid. (In the United States, the size is one quart) The Funnel "viscosity" is informed by way of seconds and used a pointer for the relative stability of fluids. The most viscous fluid means a longer time to seal one quart. Adjustment of the Marsh Funnel period is 28 seconds apiece quart for the freshwater. Typical Marsh Funnel is presented in (Fig. 1a). Flow performance of the Marsh funnel is simulated arithmetically by M.J. Pitt equation consequently; his simulation is responsible for an overall image of the sense of Marsh funnel period and a parallel permitting this to be renewed into apparent viscosity of non-Newtonian fluids. Equation (1) is for Pitt (2000).

$\mu \mathrm{e}=\rho(\mathrm{t}-25)$

Where: $\mu e=$ effictive viscosity (cp); $\rho=$ density $(\mathrm{gm} / \mathrm{cc}) ; \mathrm{t}=$ time ( $(\mathrm{sec}$.

The model existing in this work can guess the apparent viscosity in place of effective viscosity hinge on Pitt's equation; in this study, we used experimental data as an alternative of numerical. 


\section{Mixer}

Hydraulic mud mixer is an essential portion of the drilling procedure to develop a homogeneous mix of mud (Fig. 1b).

\section{PH Meter}

PH meter is an electrical device using cut-glass electrodes for the $\mathrm{PH}$ of the tester. $\mathrm{PH}$ meter is the best perfect method for evaluating $\mathrm{PH}$.

\section{Van VG Meter}

Likewise is identified by way of direct-representative viscometer. It is used for measuring mud viscosity. Two speeds of rotation are used which are 300 and $600 \mathrm{rpm}$. Bingham plastic rheological factors are simply evaluated from the direct-showing viscometer readings: PV (in units of $\mathrm{cp})=600$ dial -300 dial and YP (in units of lb/100 ft2) $=300$ dial $-\mathrm{PV}(\mathrm{Max}, 1974)$.

\section{Mud Balance}

The mud balance likewise identified by way of a mud scale is a tool used for measuring the density or weight of mud, cement or any sort of liquid. Calibration is done by using a liquid of identified density (Bourgoyne, 1991), frequently water, and as illustrated in (Fig. 1c).

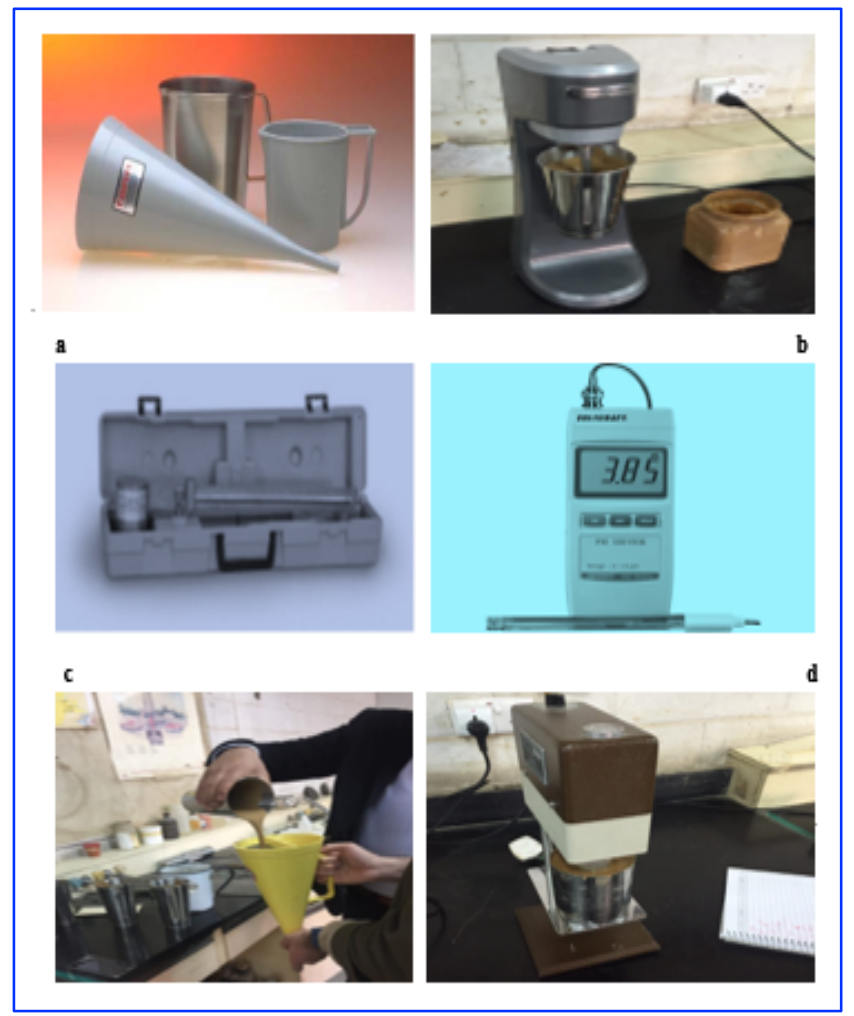

Fig. 1. The used laboratories tools (a) Marsh funnel (b) Mixer (c) Mud balance (d) pH meter (e) Funnel test and (f) Viscometer 


\section{MATERIALS}

\section{Bentonite}

Marketable Bentonites is used as drilling mud, is naturally happening clays and are extracted in many zones over the world. There are three-layer growth clays of which the maximum primary formula is calcium, but also sodium. Since the structure of Bentonite has the facility to hydrate in the existence of water. Bentonites are used to viscosity drilling muds (Winson, 1965).

\section{Barite $\mathrm{BaSO}_{4}$}

Barite collected as barium sulfate $\left(\mathrm{BaSO}_{4}\right)$. It gets that designation from Greek word "bars" that means "heavy". That term is in reply to barite's extraordinary specific gravity about 4.5. Barite frequently happens as concretions or void-filling crystals in sedimentary rocks. It is exclusively public by way of concretions and vein fillings in limestone (Ogbeide and Igbinere, 2016).

\section{Lignite}

Is another product which is used like a thinner. It has more resistant for the thermal degradation comparing with lignosulfonate (Annudeep, 2012).

\section{Carboxyl Methyl Cellulose (CMC) $\mathrm{HOCH}_{2} \mathrm{COONA}$}

If the cellulose is responded with sodium monochloroacetate, a sodium methyl acetat is replaced with three hydroxyl collections. In general, CMC has a DS in the range of 0.4 to 0.8 which is necessary for solubility (Assi et al., 2018).

\section{EXPERIMENTAL WORK}

From time to other, the driller taking mud sample from hole to check it. Marshfunnel is the easiest and fast way to check if there is any increase or decrease in the mud properties.We take sample and then comparing its properties with those of the origin sample,and will give us chance to check if there is any change in the mud properties to treat it. Through drilling operation, there is many layers contain sand, shale, limestone and formation fluids, all those contaminate the drilling fluid and lead to change in its properties. Not only viscosity change but also mud density may be change. Apparent viscosity is a unique mud rheological properties. Apparent viscosity measured by using rheometer or van-vgmeter. Observing apparent viscosity through drilling processes is essential for preventing many problems. Mud Density used for governor subsurface pressures and alleviated the wellbore. The density of the mud needs to be organized to be responsible for sufficient hydrostatic head for preventing the entry of the formation fluids, on the other hand, not so extraordinary by way of causing loss. Mud density usually measured by mud 
balance. Mud balance adjusted using freshwater must offer a reading of $8.3 \mathrm{lb}$. /gal., The governor of various mud system properties are subject to $\mathrm{pH}$; in other words, the discovery and management of contaminants, for instance, cement and soluble carbonates (Fig. 1d). The viscosity was measured by using Van VG meter (Fig. 1e). The funnel is aimed that each $1500 \mathrm{ml}$ of mud would be discharged through funnel. A slight stopwatch is prepared to Amount the sum of seconds necessary for one liter (or one US quart) of the tester to movement from Funnel into the graduated container (Fig. 1f).

\section{RESULTS AND DISCUSSION}

Marsh Funnel is one of the oldest and simplest tools which is used for determining viscosity on the routine, foundation is beneficial only for qualified comparisons. On the other hand the general conception is if the time of the rate of flow in seconds is reduced, that mean the viscosity decrease and vice versa is correct. However, weighting materials also have an effect on funnel viscosity reading and the crew who work in field operation should pay their attention for this point. Weighting resources are materials that have a high specific gravity that gives supplementary density to the mud, typically to governor formation pressure. Barium sulfate (BaSO4) or Barite is the furthermost respective weighting material. Barite specific gravity is 4.2 that sorts it conceivable to rise mud density up to $21 \mathrm{ppg}$. Nevertheless, hanging of the barite needs extraordinary gel strength. By continuing to add barite the reading of marsh decrease because of increasing friction forces between barite molecules and this causes viscosity increasing. From Figure (2), it is clear that there is a decrease in the values of apparent viscosity (Ma) and effective viscosity (Me) with increasing the quantity of barite. On the other hand ,the plastic viscosity value increase with barite additives, that increase is caused by the increase in solid content. By increasing the value of mud density, the values of funnel viscosity reading decrease, and that return to the increase in the value of hydrostatic pressure in the marsh and the gravitational force effect and as illustrated in (Fig. 3).

That point is critical and should be taken into consideration, especially in field operation; density also has an effect on funnel reading like viscosity. On the other hand, the relationship between yield point and barite additives is not stable relation some times high and some times low (Fig. 4), but we can say there is a slight increase in the value of yield point with barite additives. Since the primary function of barite increasing density (Fig. 5) and Table (1) illustrated this function. Since Marsh funnel is the most famous and quick tool that used in field operation, 
and when the crew get sample from the well and test it to show the effect of some materials on mud viscosity, he should take into his consideration that there many materials effect on funnel viscosity like weighting materials, thinners, and $\mathrm{CMC}$ and as illustraited in (Fig. 6). From Figure (7), its clear that when the soild percentage low about $1 \%$ or $2 \%$ all the tested materails gave the same value of funnel viscosity about (40-42) sec, that means at low soild percentage we cannot know which material behind that change, so we should take that point into our consideration. Here we need other device to detect which material affect on funnel viscosity reading and find the suitable treatment. On the other, hand after the 3\% soild percentage the CMC shows the highest effect on funnel viscosity and then baraite and finally thinner. Accumulation of Barite leads to a slight rise in $\mathrm{pH}$ values, as in Figure (8). Table (2) represent a part of mud report for oil well in the south of iraq, which give us a field application for how funnel viscosity affected from time to time and meter to meter by material that coming from well while drilling (formation cutiing and fluid), also from that report we can see that there is a relation between density and viscosity and there are decreasing in the value of funnel viscosity with density increasing.

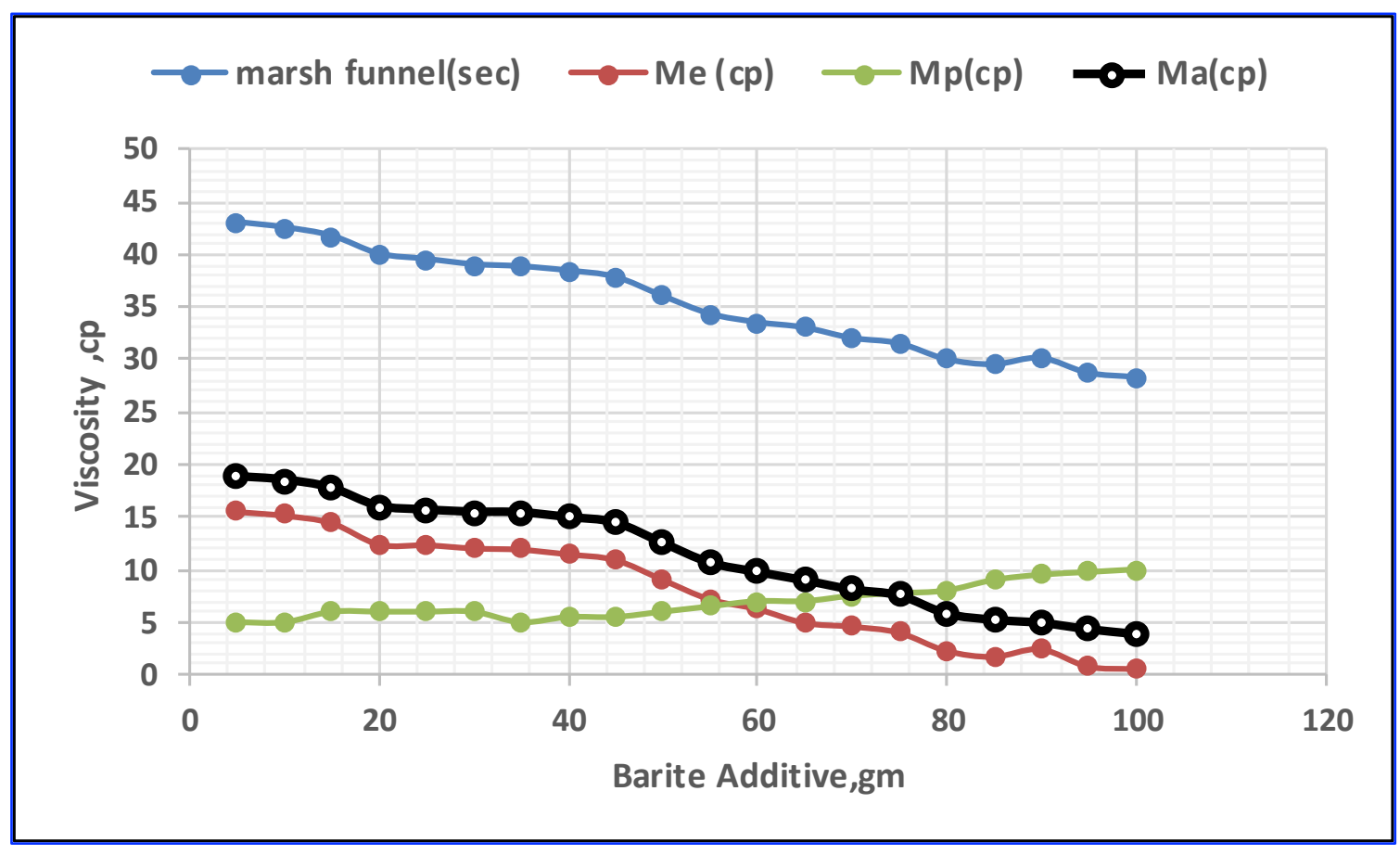

Fig. 2. Me, Ma, Mp and funnel viscosity Vs. additives of barite 


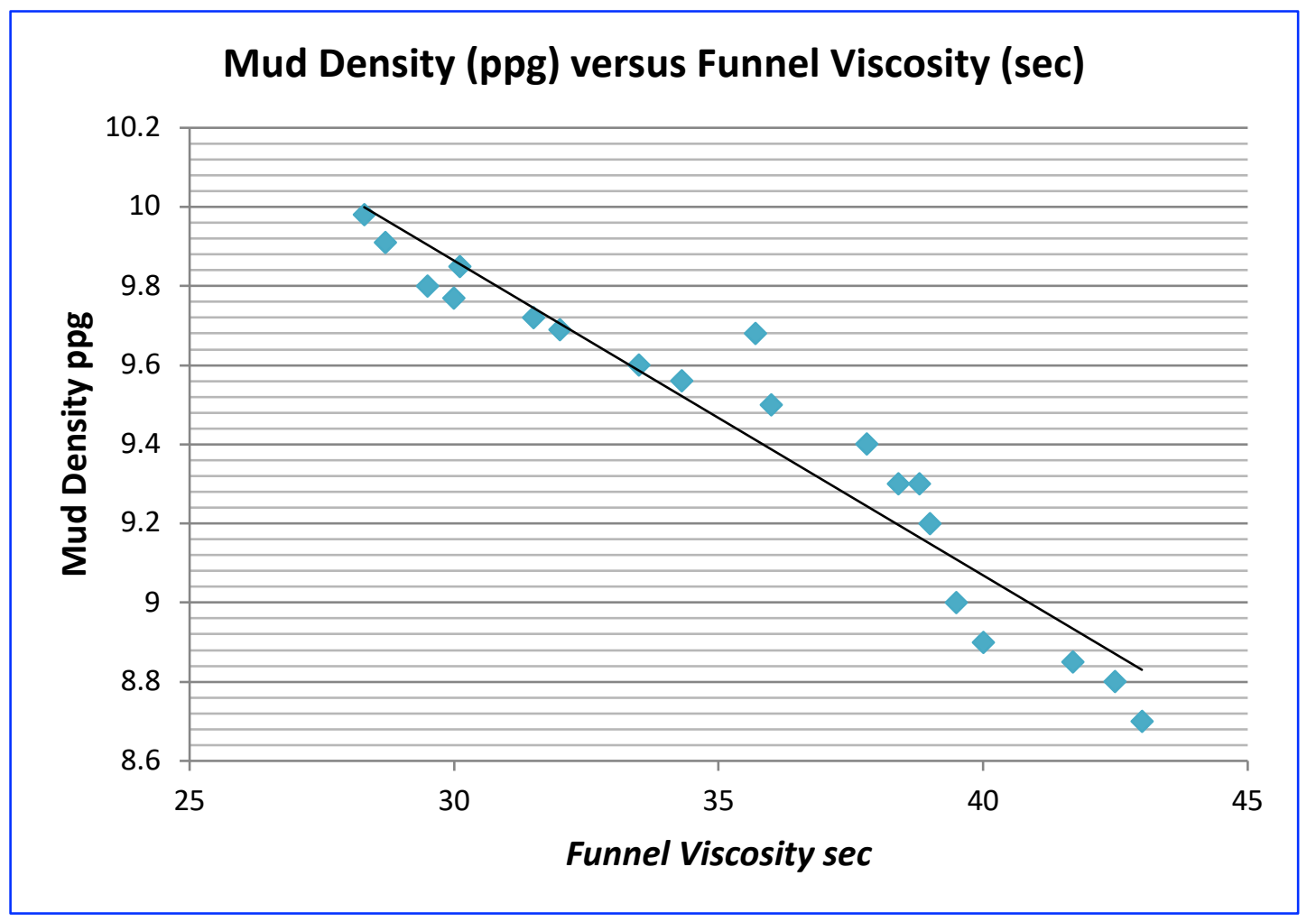

Fig. 3. $\rho$ Mud vs Marh funnel readings

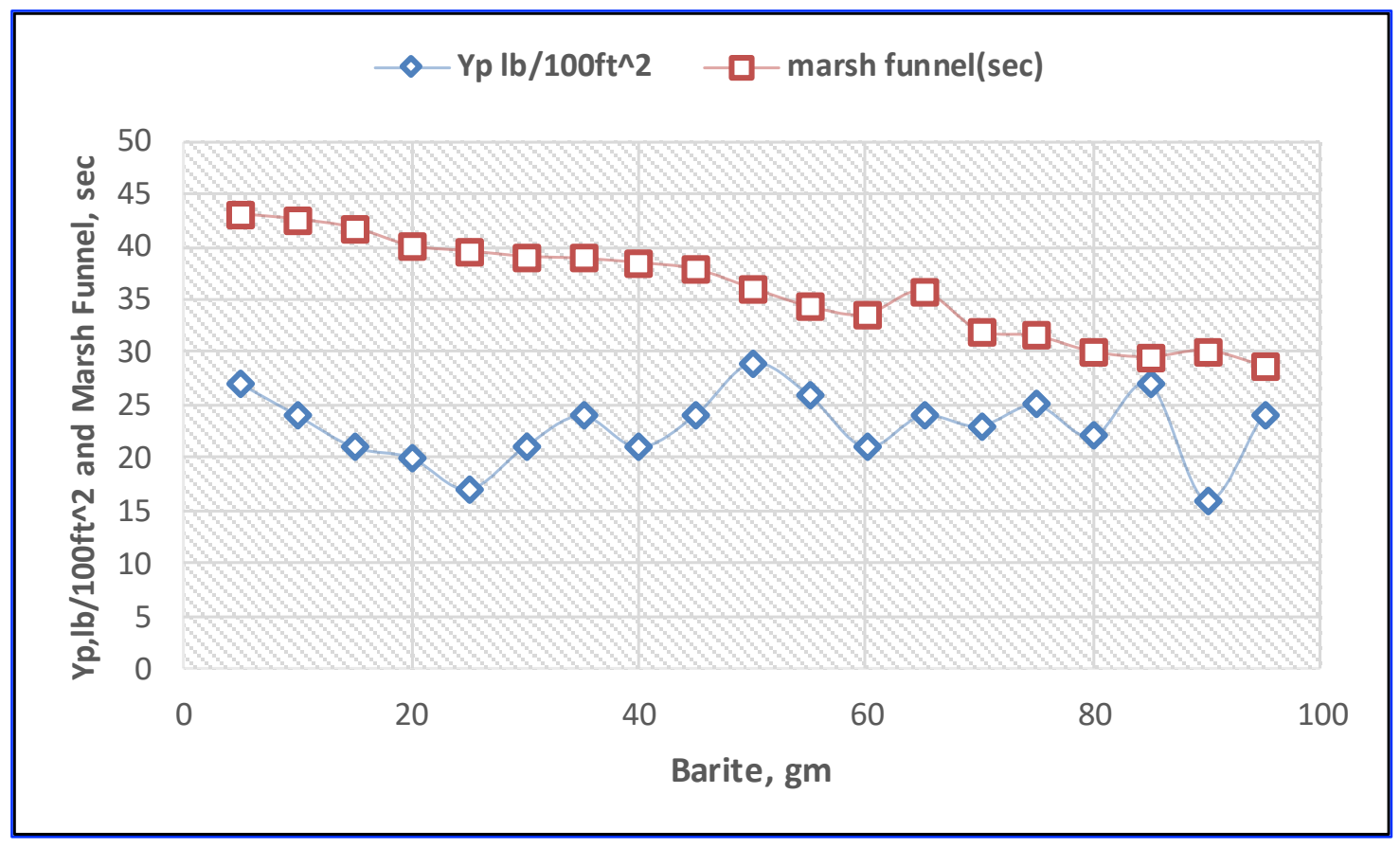

Fig. 4. Change of Yp and funnel Vs barite additives 


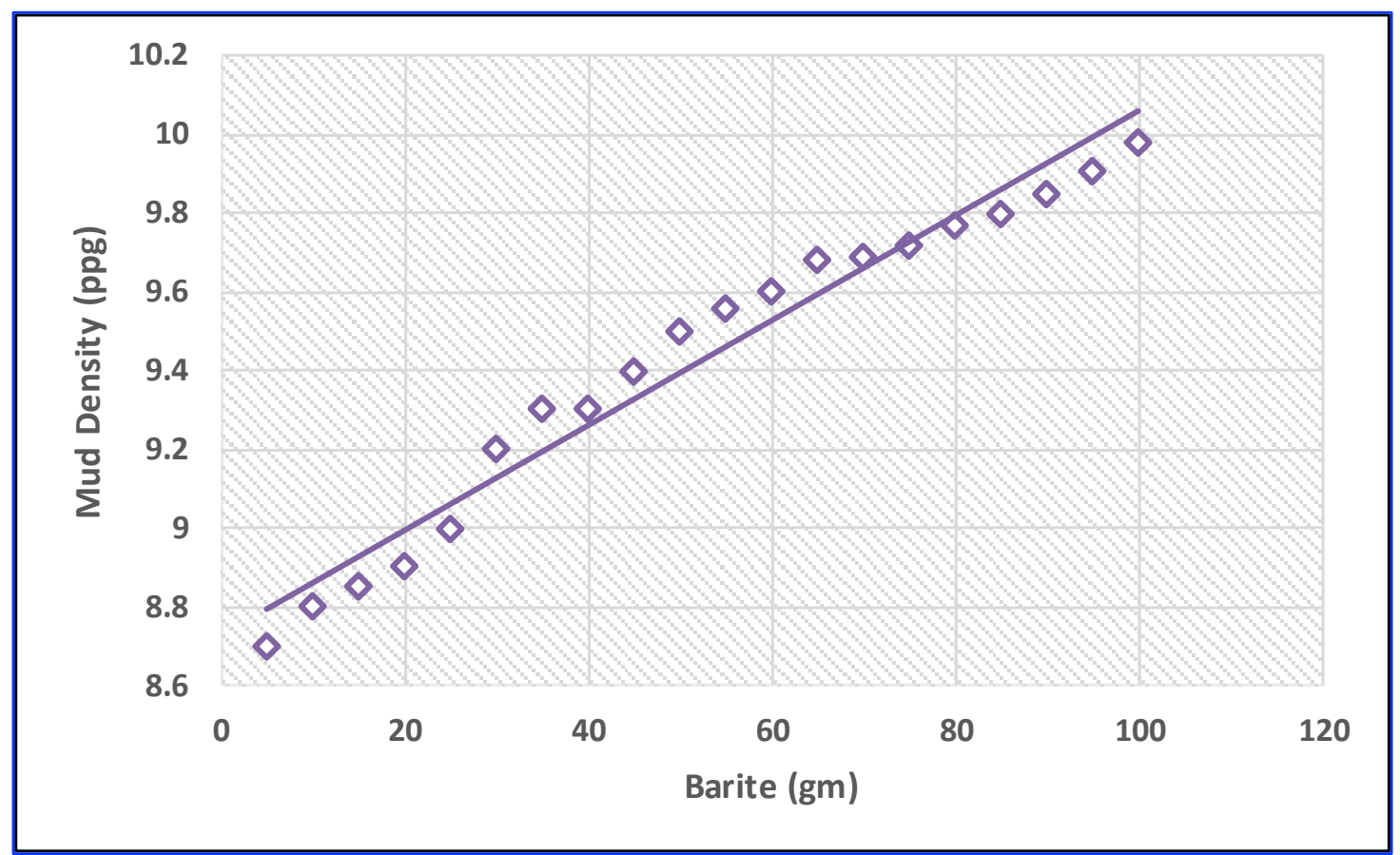

Fig. 5. $\rho$ mud Vs additives of baraite

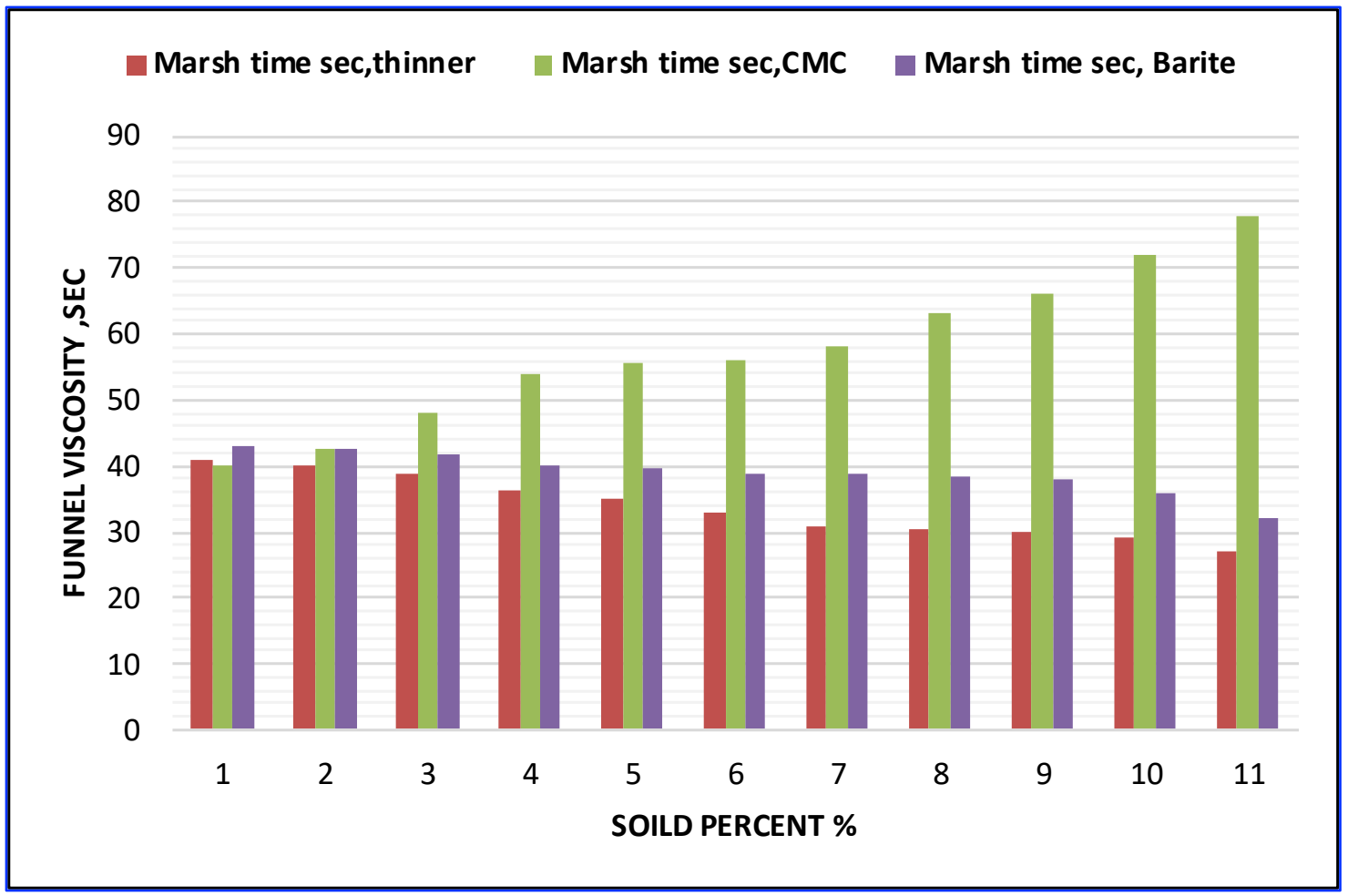

Fig. 6. The effect of weighting materials (batite), thinners and CMC on funnel viscosity 


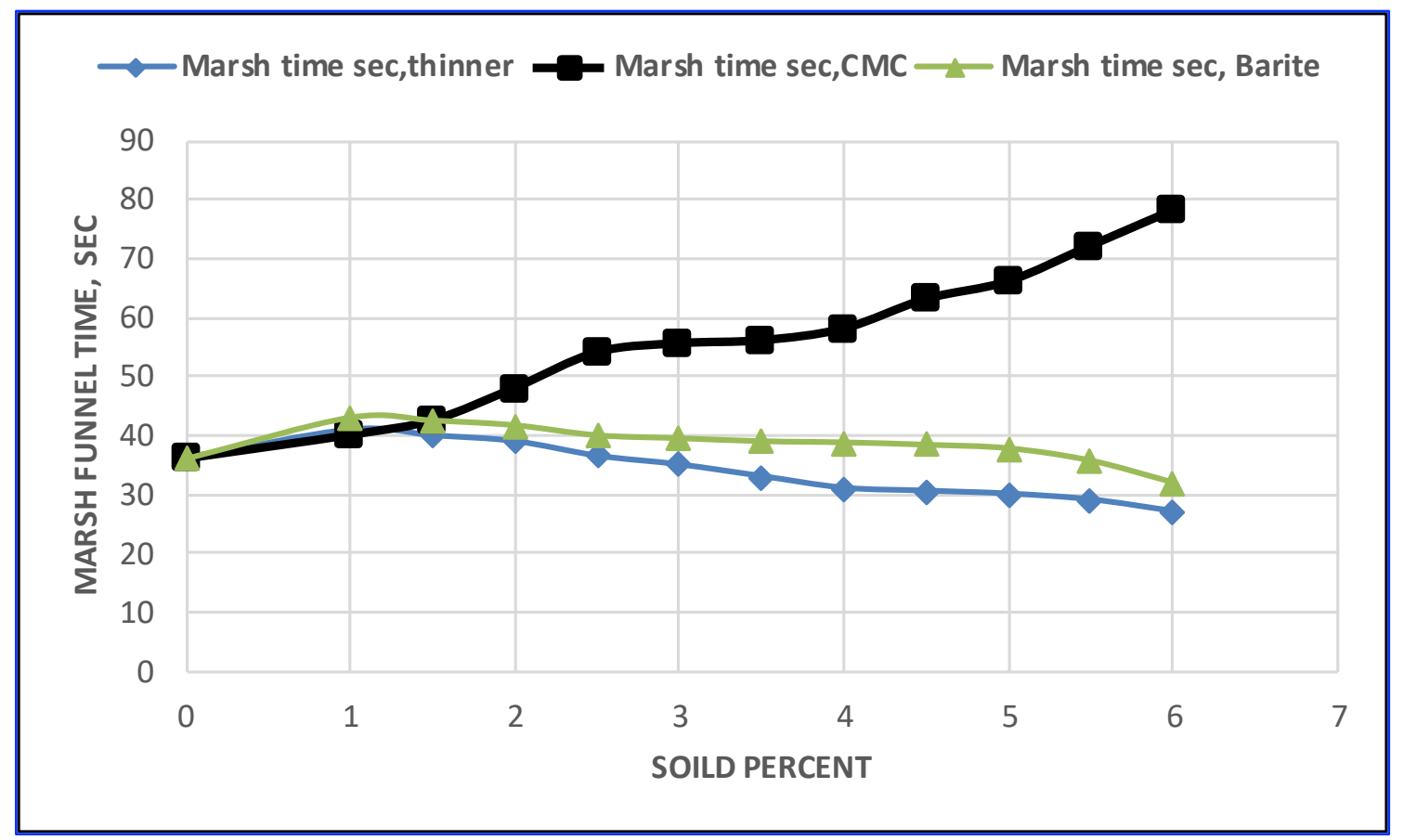

Fig. 7. The effect of some materials on the funnel viscosity readi

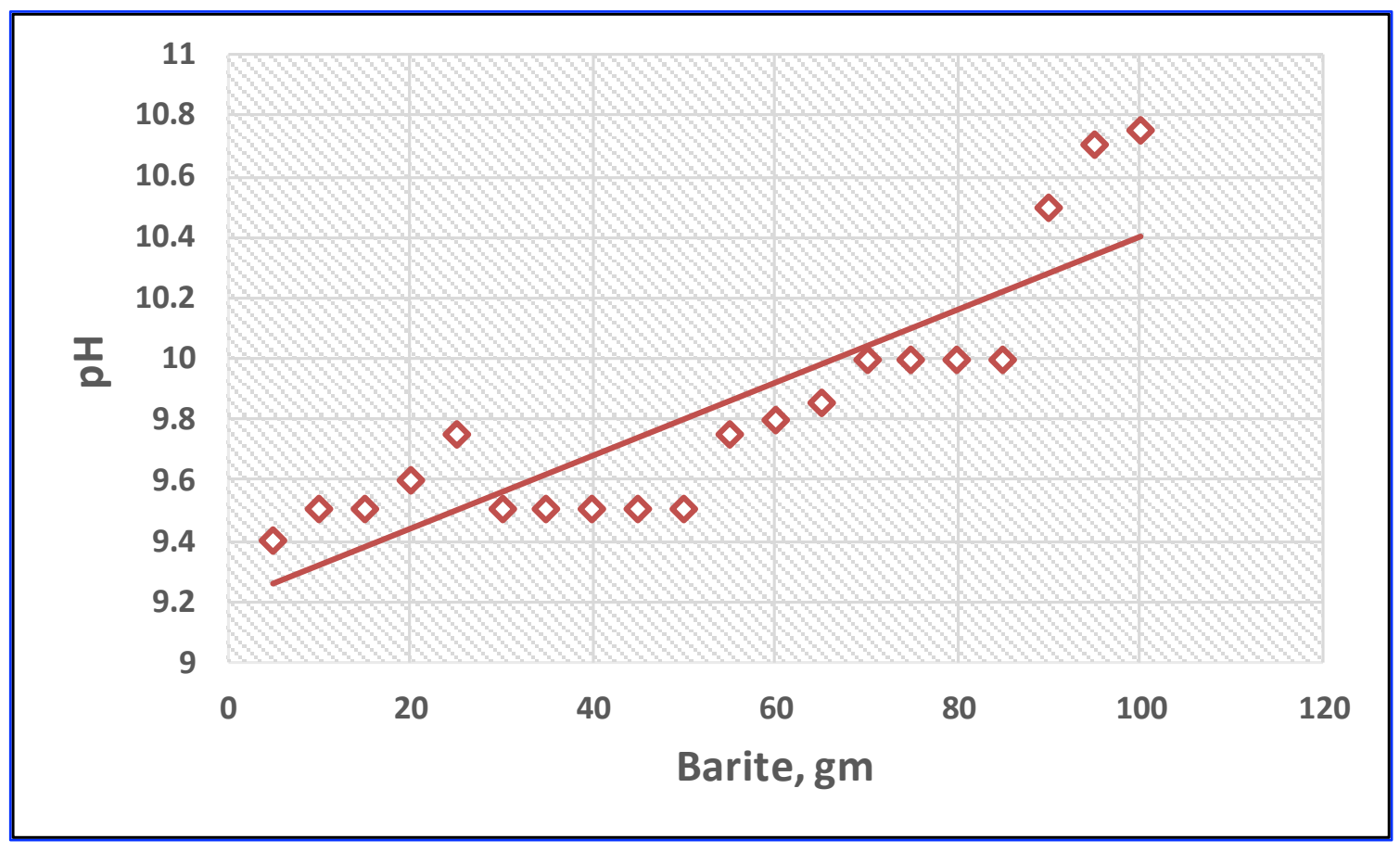

Fig. 8. The effect of barite on $\mathrm{pH}$ value 
Table 1. Summery of the laboratory results

\begin{tabular}{|c|c|c|c|c|c|}
\hline Barite(gm) & Mud density ppg & Marsh funnel(sec) & Ma (cp) & Mp(cp) & Yp lb/100ft`2 \\
\hline 5 & 8.7 & 43 & 18.8 & 5 & 27 \\
\hline 10 & 8.8 & 42.5 & 18.5 & 6 & 24 \\
\hline 15 & 8.85 & 41.7 & 17.7 & 7 & 21 \\
\hline 20 & 8.9 & 40 & 16.0 & 6 & 20 \\
\hline 25 & 9 & 39.5 & 15.7 & 7 & 17 \\
\hline 30 & 9.2 & 39 & 15.5 & 6 & 21 \\
\hline 35 & 9.3 & 38.8 & 15.4 & 5 & 24 \\
\hline 40 & 9.3 & 38.4 & 15.0 & 7 & 21 \\
\hline 45 & 9.4 & 37.8 & 14.4 & 5 & 24 \\
\hline 50 & 9.5 & 36 & 12.5 & 3.5 & 29 \\
\hline 55 & 9.56 & 34.3 & 10.7 & 4 & 26 \\
\hline 60 & 9.6 & 33.5 & 9.8 & 5 & 21 \\
\hline 65 & 9.68 & 35.7 & 12.4 & 3.5 & 24 \\
\hline 70 & 9.69 & 32 & 8.1 & 4 & 23 \\
\hline 75 & 9.72 & 31.5 & 7.6 & 5 & 25 \\
\hline 80 & 9.77 & 30 & 5.9 & 5 & 22 \\
\hline 85 & 9.8 & 29.5 & 5.3 & 5 & 27 \\
\hline 90 & 9.85 & 30.11 & 6.0 & 8 & 16 \\
\hline
\end{tabular}

Table 2. Part of mud report for oil well in south of Iraq

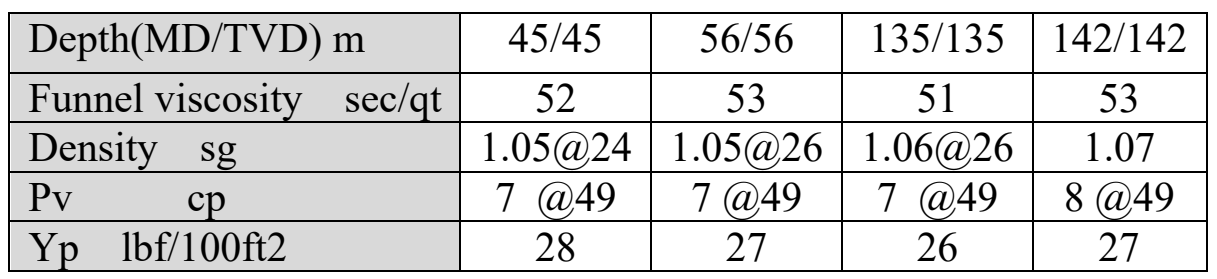

\section{CONCLUSIONS}

1. Adding barite leads to rising the density, viscosity and Yp of the drilling mud.

2. Adding barite have an affects on the Marsh funnel reading, in other words, reduce the funnel viscosity reading.

3. Barite leads to time dropping for the fluid to release as a result of the increasing in the value of the hydrostatic pressure.

4. Adding barite reduce the value of Me.

5. Accumulation of barite leads to a slight rise in $\mathrm{pH}$ values. 
6. The consequences showed that Mud density is another factor that affects funnel viscosity, and this point should be taken into consideration especially in-field testing.

7. Increasing in viscosity leads to an increase in the funnel viscosity reading, while increasing in density leads to a decrease in the funnel viscosity reading.

8. Adding thinner leads to reduce the value of the funnel viscosity.

\section{Nomenclature}

$\mathrm{CMC}=$ carboxyl methyl cellulose.

PV: plastic viscosity (cp)

$\mu \mathrm{a}$ :apparent viscosity (cp)

YP: Yield Point, lb/100ft ${ }^{2}$

Me: effective viscosity (cp)

\section{ACKNOWLEDGMENTS}

The authors are very grateful to the editor in chief Prof. Dr. Salih M. Awadh, the secreatry of Journal Mr. Samir R. Hijab. and head of the technical editors Dr. Heba S. Al-Mimar for their great efforts and valueble comments.

\section{REFERENCES}

Abdul Majeed, R. K., and A.ALhaleem, A. A., 2020. Estimation of shear wave velosity from wireline logs data for Amara oil field, Mishrif Formation,southren Iraq, Iraqi Geological Journal, 53(1A): 36-47.

Ahmadi, T., 2007. Behaviour of suspensions and emulsions in drilling fluids. Annual transactions of the nordic rheology society, 15 (22):88-101.

Annudeep, S. D, 2012 . Rheological Properties and Corrosion Characteristics of Drilling Mud Additives . Dalhousie University, Halifax, Nova Scotia, PDF.

Assi, A. H., 2017. Enhancing the lifting capacity of drilling fluids in vertical oil wells, Iraqi Journal of Chemical and Petroleum Engineering, 18 (3): 13-29.

Assi, A. H., Khazeem, R. R., Salem, A. S., and Ali, A. T., 2018. Studying the effects of different polymers on rheological properties of water base muds. Journal of Engineering, 10 (23): 97-106.

Bourgoyne, A. T., Millheim, K. K., Chenevert, M. E., and Young, F. S., 1986. Applied Drilling Engineering", Society of Petroleum Engineers Text Book Series., Richardson, TX, 1.

Bourgoyne, A. T., Chenevert, M. E., Millheim, K. K., Young Jr., F. S., 1991. Applied Drilling Engineering, SPE Textbook Series, Society of Petroleum Engineers, Richardson, TX, 2 .

Marsh, H., 1931. Properties and Treatment of Rotary Mud .Petroleum Development and Technology, Transactions of the AIME, 234-251.

Matthew, T., 2011. Rheological and yield stress measurements of non- newtonian fluids using a Marsh funnel. Journal of Petroleum Science and Engineering, 77(12): 393-402.

Max, R. A., 1974. Drilling Fluid Technology, PDF, Exxon Company, U.S.A.

Ogbeide, P.O., and Igbinere, S. A., 2016 .The effect of additives on rheological properties of drilling fluid in highly

Pitt, M. J., 2000. The Marsh funnel and drilling fluid viscosity: a new equation for field use.Soc. Petroleum Eng., Drilling Completions, 1 (15): (3-6).

Power, D., and Zamora, M., 2003. Drilling Fluid Yield Stress: Measurement Techniques for Improved Understanding of Critical Drilling Fluid Parameters,. AADE-03-NTCE-35, AADE Technical Conference, Houston, deviated wells, 22(17):47-56.

Winson, R.W., 1965. Drilling fluid industrial minerals and rocks and rheological properties of drilling fluid World Oil, 12 (18): 33-49. 